Supplement of Weather Clim. Dynam., 1, 427-443, 2020

https://doi.org/10.5194/wcd-1-427-2020-supplement

Weather and

(c) Author(s) 2020. This work is distributed under the Creative Commons Attribution 4.0 License.

(c) (1)

Supplement of

\title{
Future wintertime meridional wind trends through the lens of subseasonal teleconnections
}

Dor Sandler and Nili Harnik

Correspondence to: Dor Sandler (dor.sandler@gmail.com)

The copyright of individual parts of the supplement might differ from the CC BY 4.0 License. 


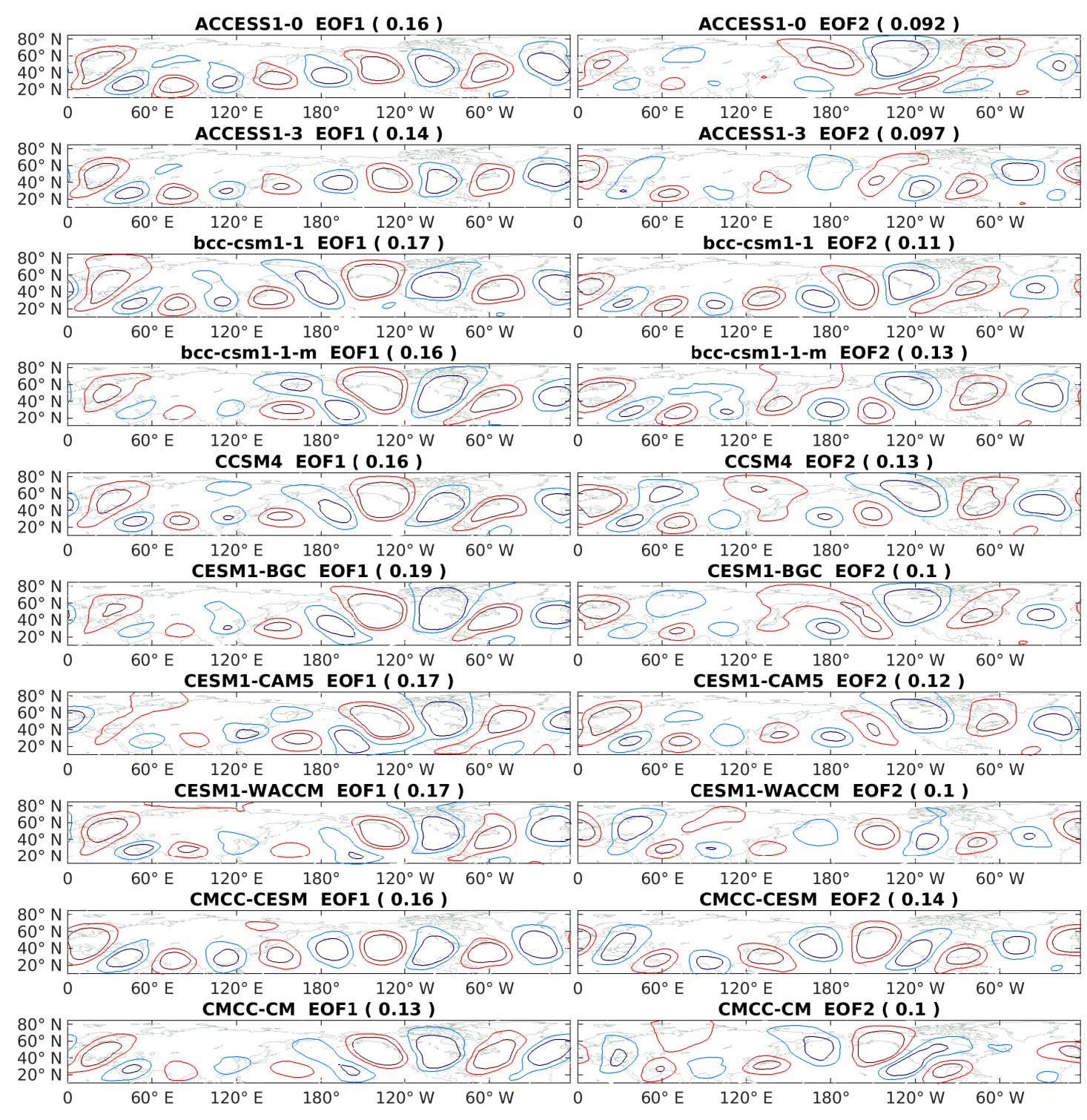

Figure S1. Individual CMIP5 models' first two leading V EOFs, based on Historical DJF data - 300hPa monthly subseasonal anomalies for the entire NH. The $\lambda$ value for each EOF is denoted in parentheses in the titles. Positive (negative) values are displayed in red (blue), with an interval of $1 \mathrm{~ms}^{-1}$. Contours greater than $2 \mathrm{~ms}^{-1}$ were omitted for clarity. 


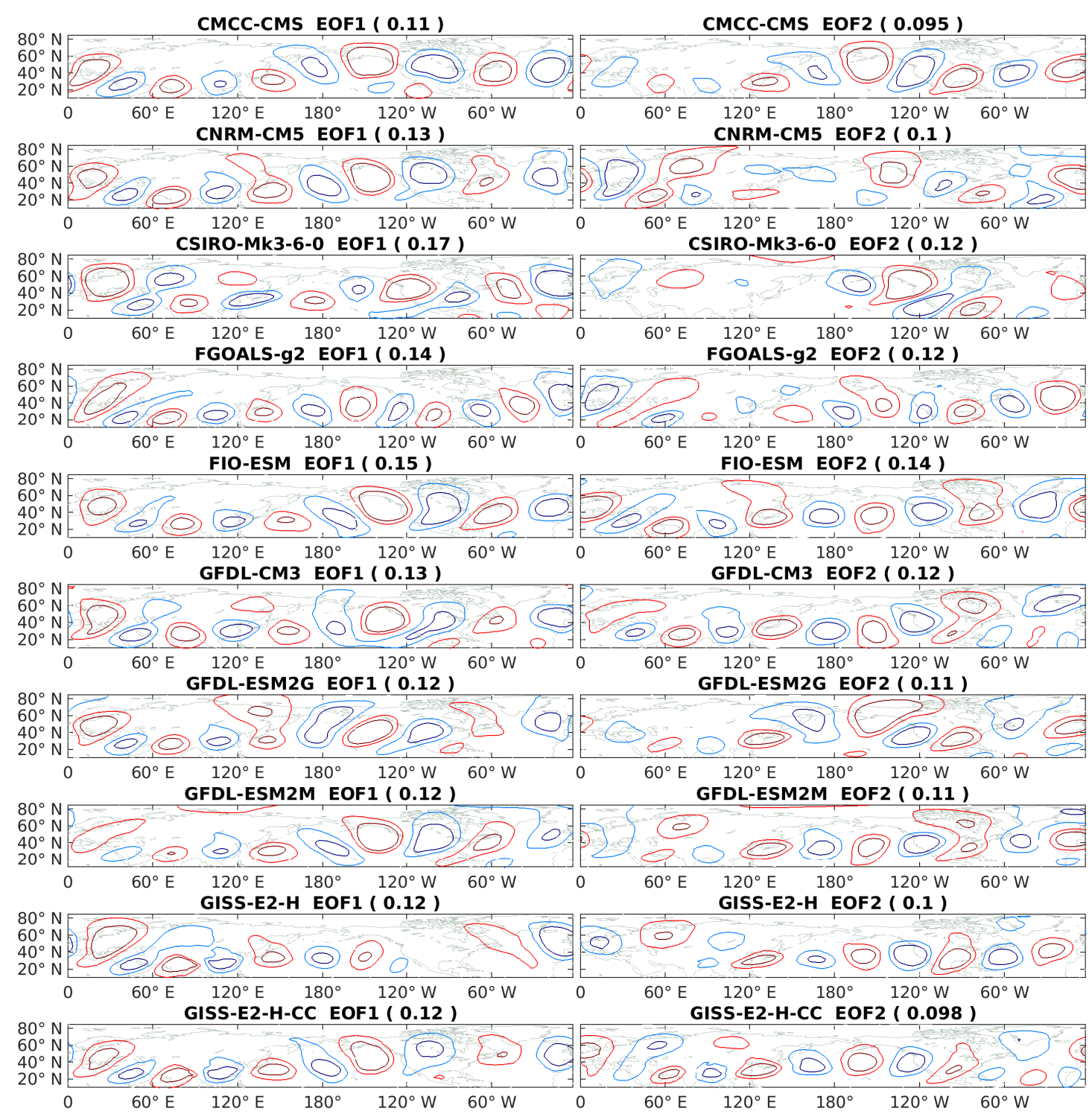

Figure S1. Individual CMIP5 models' first two leading V EOFs, based on Historical DJF data - 300hPa monthly subseasonal anomalies for the entire NH. The $\lambda$ value for each EOF is denoted in parentheses in the titles. Positive (negative) values are displayed in red (blue), with an interval of $1 \mathrm{~ms}^{-1}$. 


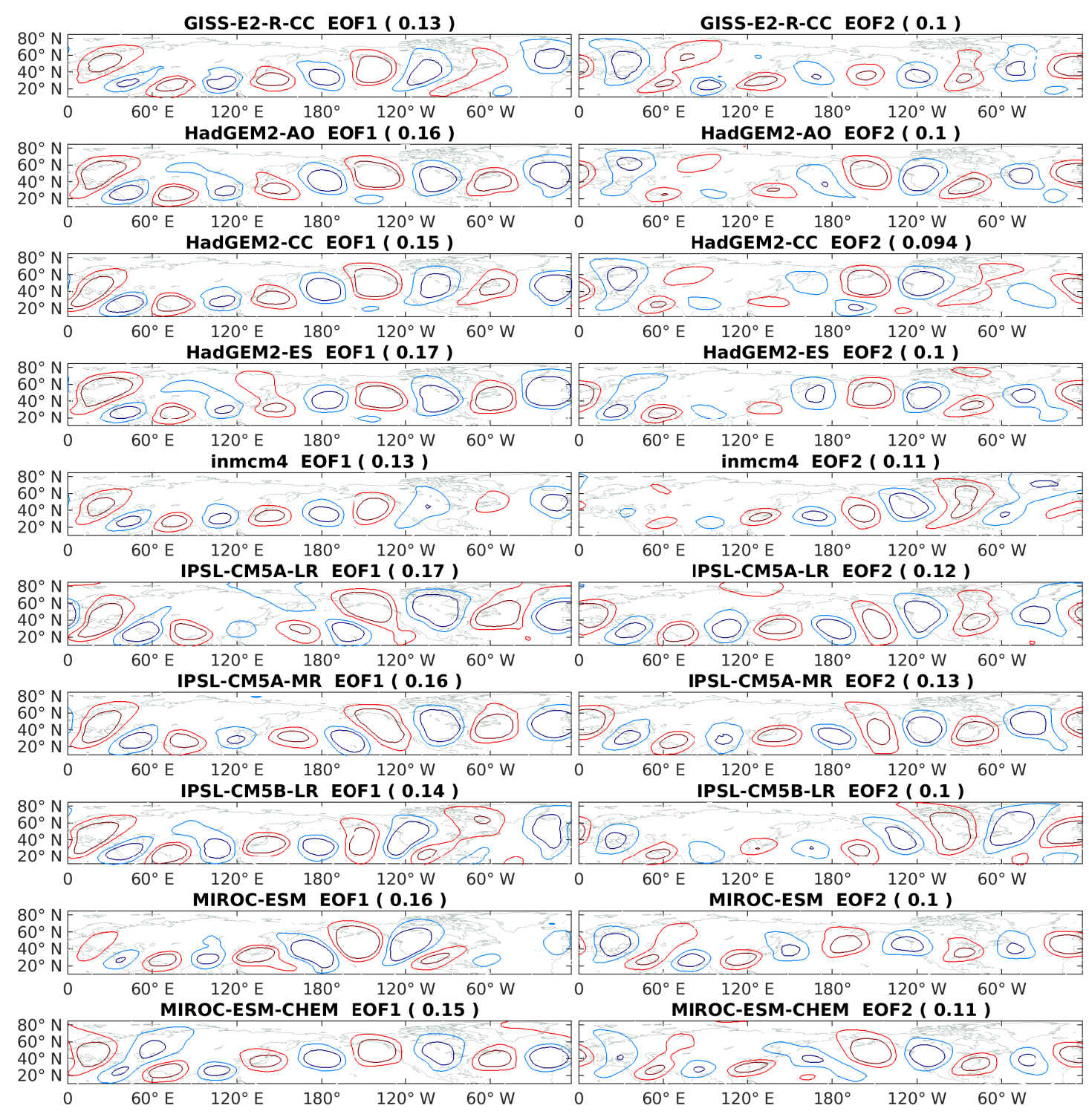

Figure S1. Individual CMIP5 models' first two leading V EOFs, based on Historical DJF data - 300hPa monthly subseasonal anomalies for the entire NH. The $\lambda$ value for each EOF is denoted in parentheses in the titles. Positive (negative) values are displayed in red (blue), with an interval of $1 \mathrm{~ms}^{-1}$. 


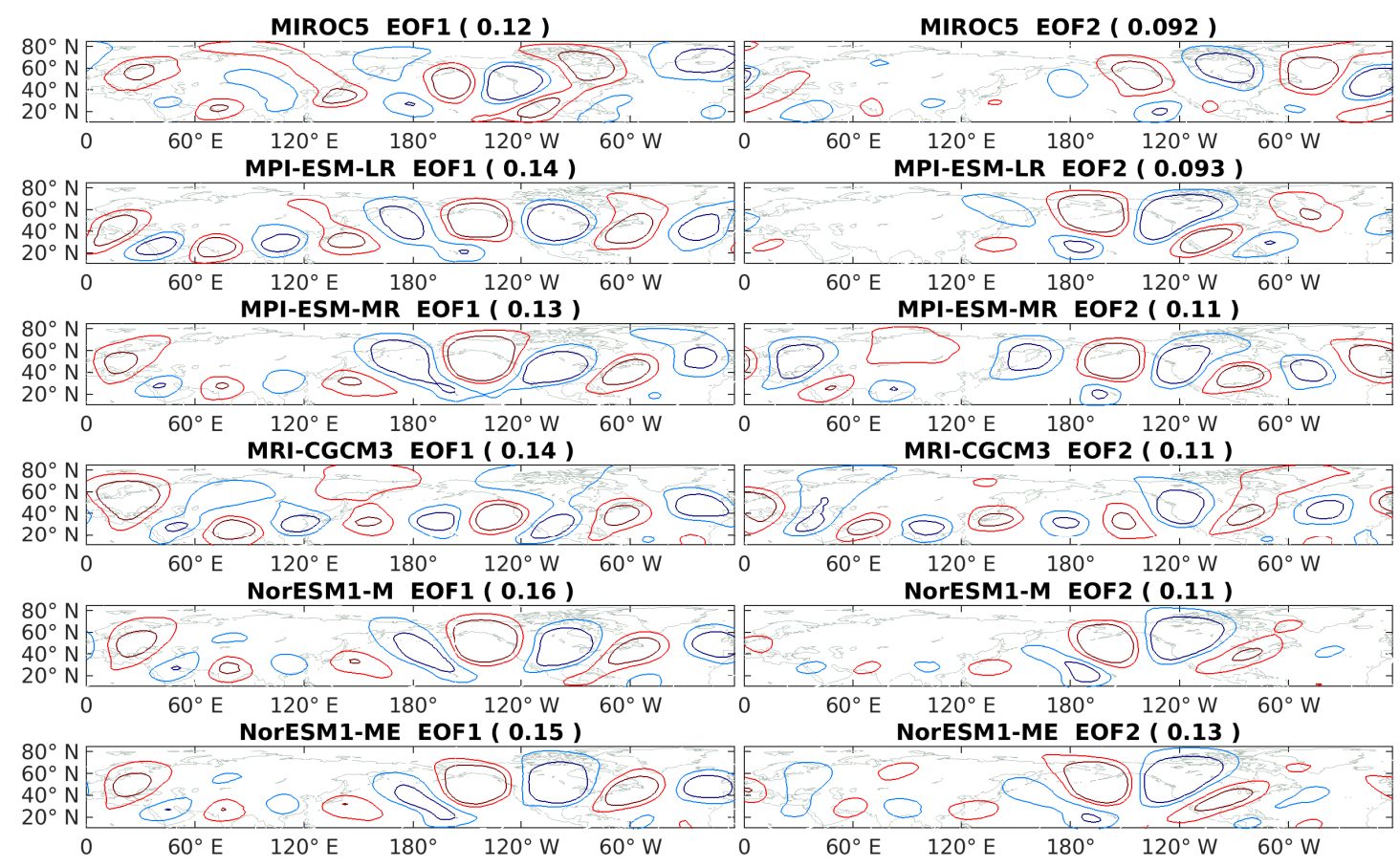

Figure S1. Individual CMIP5 models' first two leading V EOFs, based on Historical DJF data - 300hPa monthly subseasonal anomalies for the entire NH. The $\lambda$ value for each EOF is denoted in parentheses in the titles. Positive (negative) values are displayed in red (blue), with an interval of $1 \mathrm{~ms}^{-1}$. 


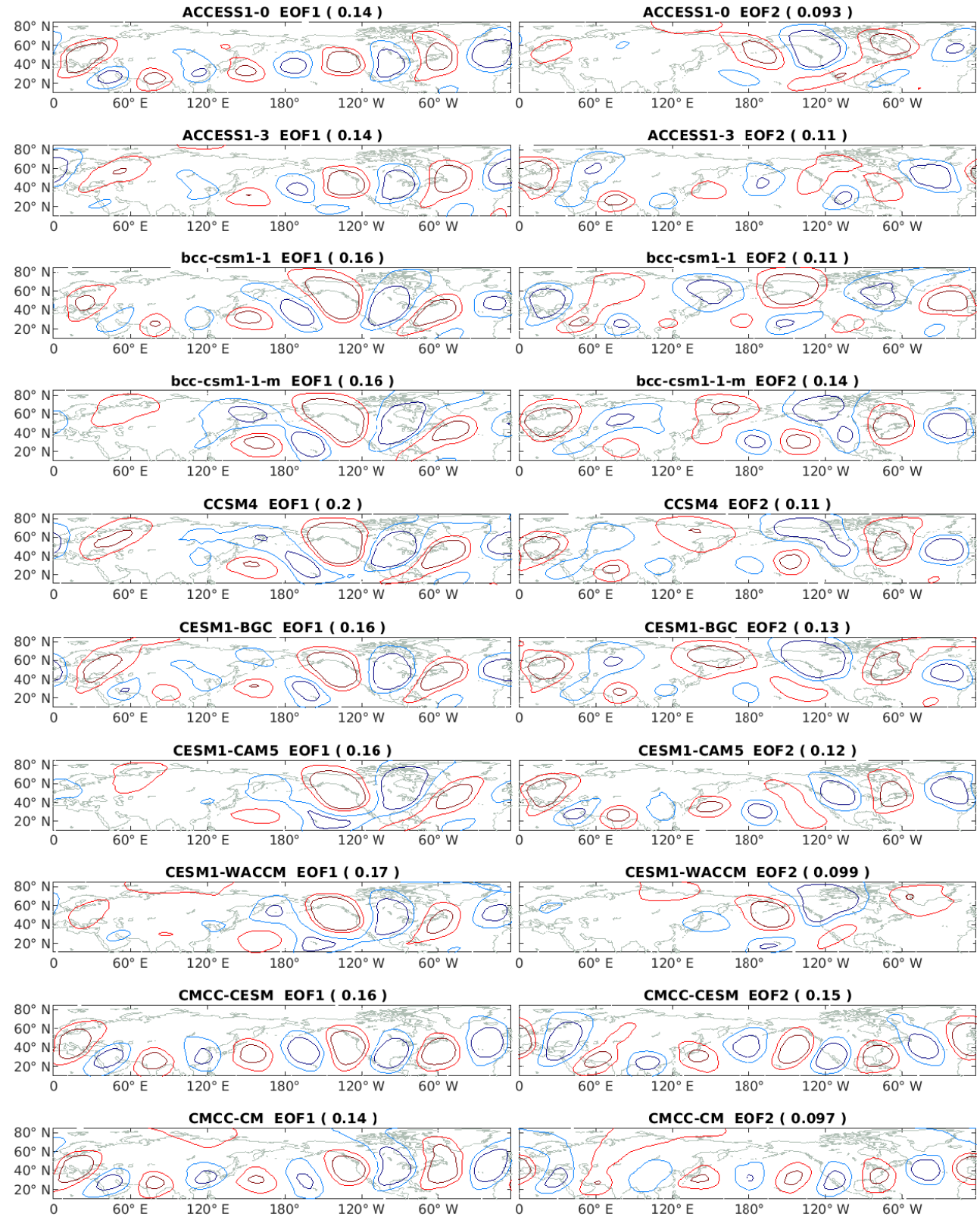

Figure S2. Same as Fig. S1, but for EOFs calculated with RCP8.5 runs. 


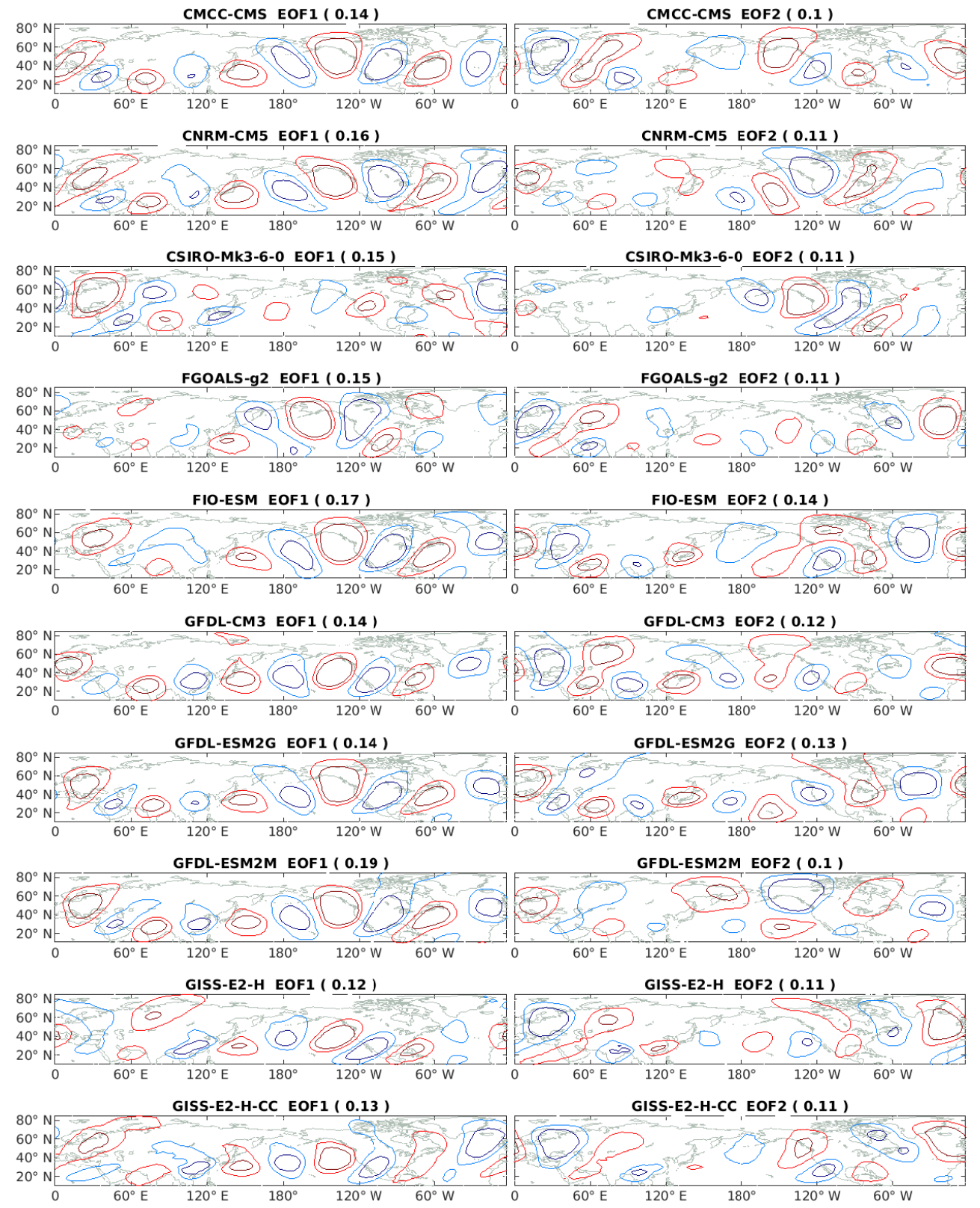

Figure S2. Same as Fig. S1, but for EOFs calculated with RCP8.5 runs. 


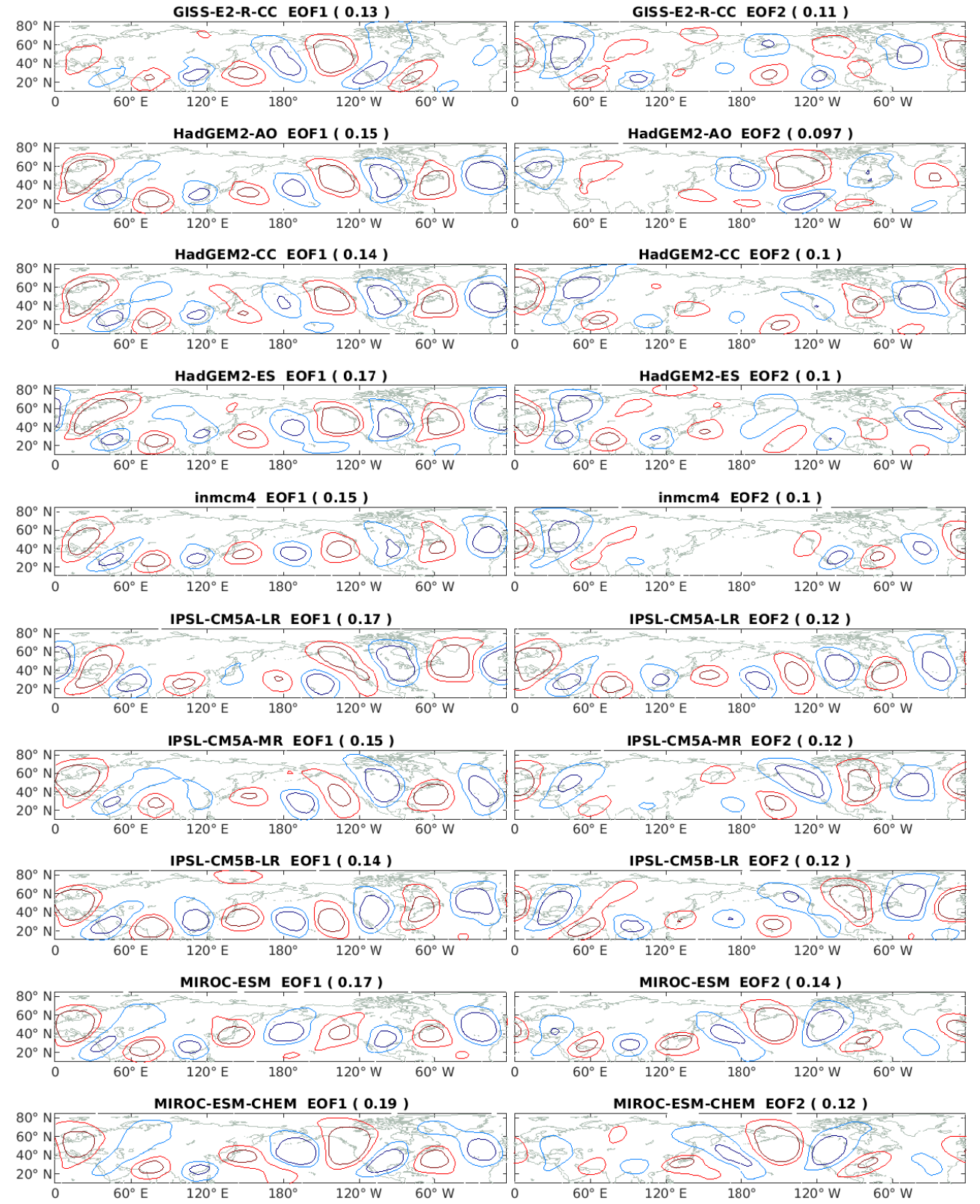

Figure S2. Same as Fig. S1, but for EOFs calculated with RCP8.5 runs. 

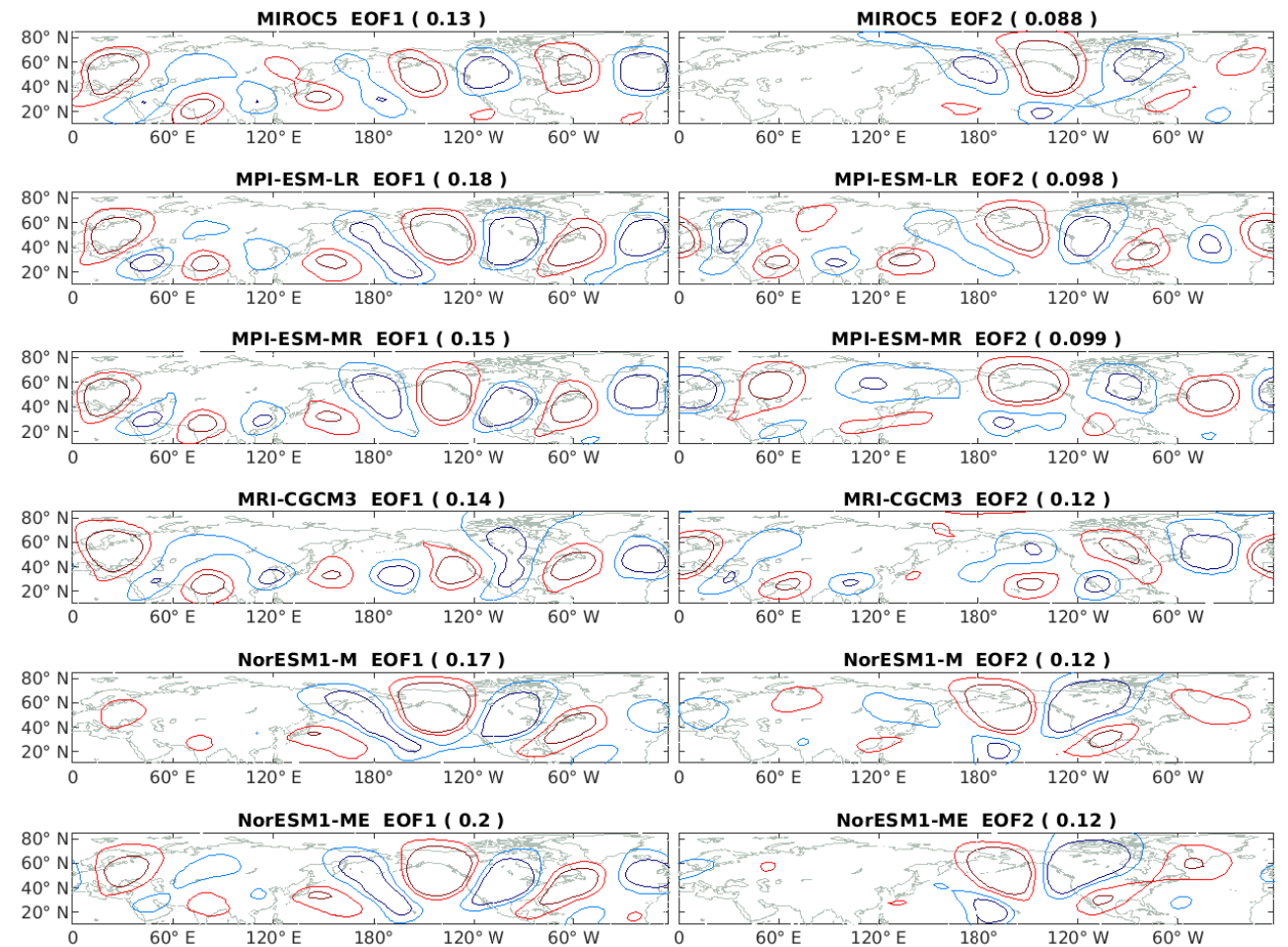

Figure S2. Same as Fig. S1, but for EOFs calculated with RCP8.5 runs. 


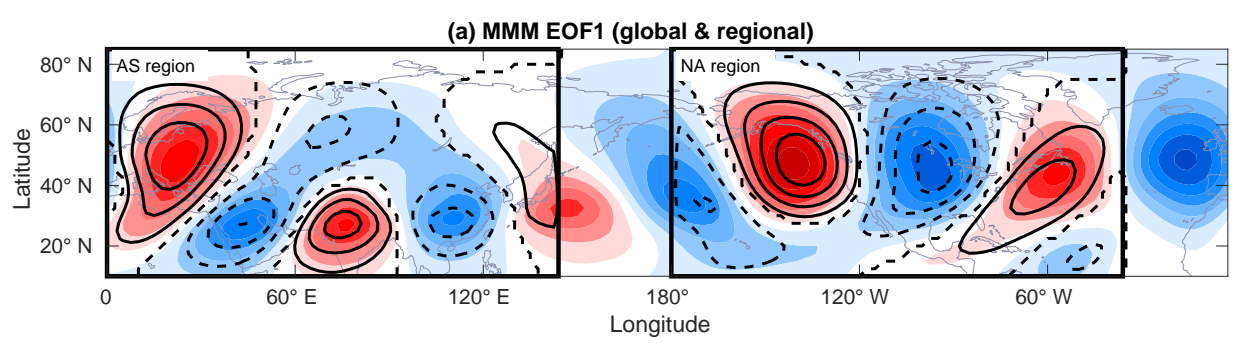

(b) MMM EOF2 (global \& regional)

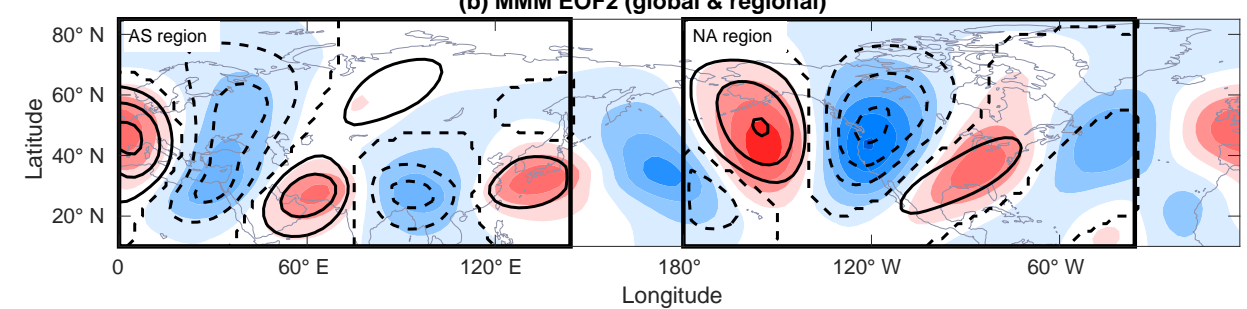

Figure S3. The first two leading Historical MMM V EOFs, calculated for the entire NH (shading) and for the NA and AS sectors (contours).

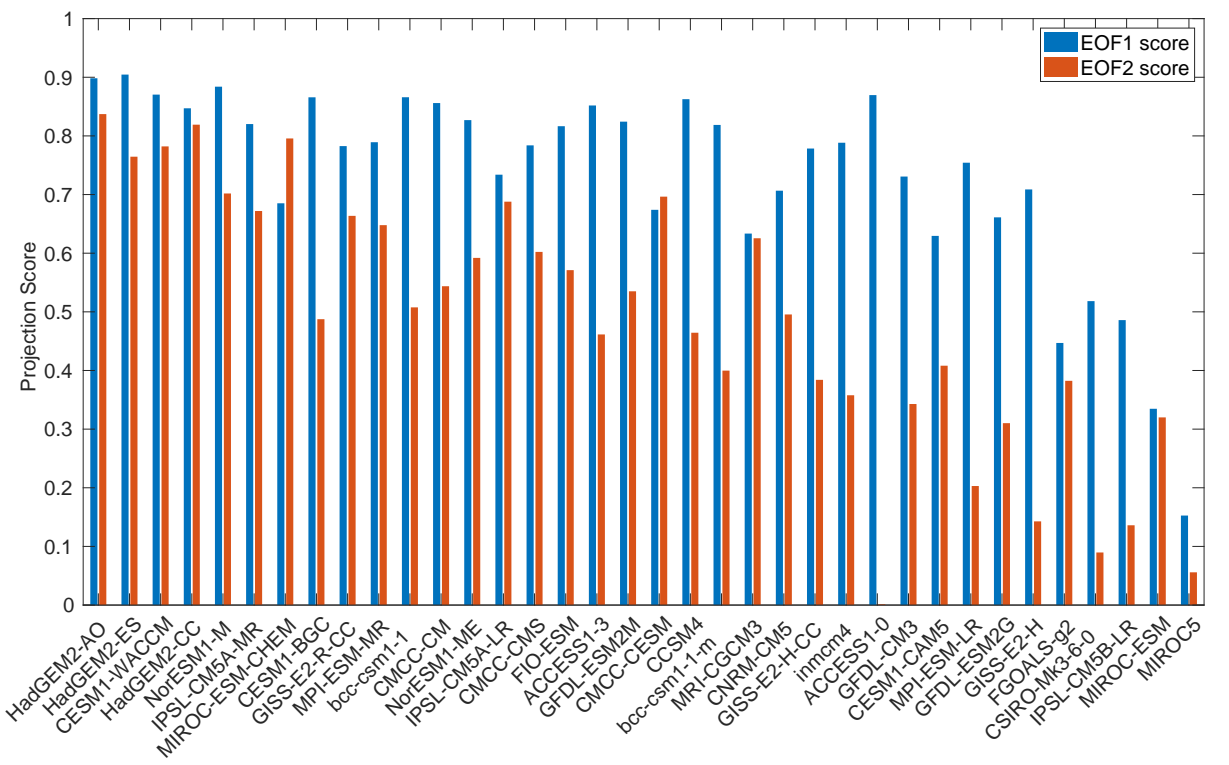

Figure S4. Model skill for EOF representation, as expressed by the Pearson correlation coefficient between the cosine latitude weighted global functions and the NCEP-I patterns.

\section{S1 Definition and filtering of CTP Events}

We define "CTP events" in daily mean data. These are essentially Rossby Wave Packets which are nearly in phase with the $500 \mathrm{hPa}$ equivalent of the preferably-phased pattern that was found in the $300 \mathrm{hPa}$ monthly projections. First, we apply a 
3-day running mean on the $500 \mathrm{hPa}$ daily $V$ field. After calculating the projection index and excluding low values (as in the 5 monthly case), we detect all sequences of 3 or more consecutive daily timesteps in which $\left|\gamma_{d}-\gamma_{m}\right| \leq \pi / 8$, where $\gamma_{d}$ and $\gamma_{m}$ are the daily and preferred-monthly phases respectively. Lag 0 of a CTP event is defined as the first day of the sequence. Two consecutive sequences that are not separated by at least 48 hours are considered one CTP event. Our results were not found to be sensitive to the choice of these parameters. This method of filtering results in some false positive matches. We therefore further filter out all sequences whose composite does not display a wavy signature (alternating mean negative-positive-negative anomalies in the boxes marked in Fig. 8c). In order to determine the statistical significance of the resulting event composites, we use a 1000 member bootstrap method.

\section{S2 Lagged linear regression of tropical proxies}

We used lagged linear regression in an attempt to establish a causal relationship between tropical convective forcing (expressed by OLR and upper tropospheric divergence) and the excitation of CTP events. After choosing a base daily time series as an independent variable $\left(X_{i}\right)$, we regress onto it the 7-day lagged time series of a chosen dependent field $\left(Y_{i}\right)$. Multiple regression equations are then derived, one for every gridpoint of $Y$. We map the resulting $Y$ pattern by plugging an identical arbitrary $x$ value in every equation. Statistical significance is assessed through the p-value of the correlation coefficient.

Following Livezey and Chen (1983), we assume that the coefficient's distribution is normal with a standard deviation of $1 / \sqrt{n-3} . n$ is the number of degrees of freedom, estimated by:

$$
n=N /\left[1+2 \sum_{i=1}^{N} C_{X X}(i \Delta t) C_{Y Y}(i \Delta t)\right]
$$

Where $N$ is the number of samples, $\Delta t$ is the sampling time (1 day) and $C_{Z Z}(i \Delta t)$ is the autocorrelation of $Z$ for lag $i \Delta t$. 
Table S1. CMIP5 models used in this study. All data was taken from monthly-resolution Historical and RCP8.5 runs. Models denoted by (*) were studied as test cases using daily data.

\begin{tabular}{|c|c|}
\hline Model Name & Institution \\
\hline $\begin{array}{l}\text { ACCESS1.0 } \\
\text { ACCESS } 1.3\end{array}$ & $\begin{array}{l}\text { Commonwealth Scientific and Industrial Research Organization } \\
\text { (CSIRO) and Bureau of Meteorology }\end{array}$ \\
\hline $\begin{array}{l}\text { BCC-CSM1.1 } \\
\text { BCC-CSM1.1(m) }\end{array}$ & Beijing Climate Center, China Meteorological Administration \\
\hline CCSM4 & National Center for Atmospheric Research, United States \\
\hline $\begin{array}{l}\text { CESM1(BGC) } \\
\text { CESM1(CAM5) } \\
\text { CESM1(WACCM) }\end{array}$ & $\begin{array}{l}\text { National Center for Atmospheric Research, United States; Community } \\
\text { Earth System Model Contributors }\end{array}$ \\
\hline $\begin{array}{l}\text { CMCC-CESM } \\
\text { CMCC-CM } \\
\text { CMCC-CMS }\end{array}$ & Centro Euro-Mediterraneo per I Cambiamenti Climatici \\
\hline CNRM-CM5 & $\begin{array}{l}\text { Centre National de Recherches Météorologiques / Centre Européen de } \\
\text { Recherche et Formation Avancée en Calcul Scientifique }\end{array}$ \\
\hline CSIRO-Mk3.6.0 & $\begin{array}{l}\text { Commonwealth Scientific and Industrial Research Organization in } \\
\text { collaboration with Queensland Climate Change Centre of Excellence }\end{array}$ \\
\hline FGOALS-g2 & $\begin{array}{l}\text { LASG, Institute of Atmospheric Physics, Chinese Academy of } \\
\text { Sciences and CESS, Tsinghua University }\end{array}$ \\
\hline FIO-ESM & The First Institute of Oceanography, SOA, China \\
\hline $\begin{array}{l}\text { GFDL-CM3 } \\
\text { GFDL-ESM2G } \\
\text { GFDL-ESM2M }\end{array}$ & NOAA Geophysical Fluid Dynamics Laboratory, United States \\
\hline $\begin{array}{l}\text { GISS-E2-H } \\
\text { GISS-E2-H-CC } \\
\text { GISS-E2-R-CC }\end{array}$ & NASA Goddard Institute for Space Studies, United States \\
\hline HadGEM2-AO & $\begin{array}{l}\text { National Institute of Meteorological Research / Korea Meteorological } \\
\text { Administration }\end{array}$ \\
\hline $\begin{array}{l}\text { HadGEM2-CC } \\
\text { HadGEM2-ES }\end{array}$ & Met Office Hadley Centre, United Kingdom \\
\hline INM-CM4 & Institute for Numerical Mathematics, Russia \\
\hline $\begin{array}{l}\text { IPSL-CM5A-LR } \\
\text { IPSL-CM5A-MR(*) } \\
\text { IPSL-CM5B-LR }\end{array}$ & Institut Pierre-Simon Laplace, France \\
\hline $\begin{array}{l}\text { MIROC-ESM } \\
\text { MIROC-ESM-CHEM(*) } \\
\text { MIROC5 }\end{array}$ & $\begin{array}{l}\text { Japan Agency for Marine-Earth Science and Technology, Atmosphere } \\
\text { and Ocean Research Institute and National Institute for Environmental } \\
\text { Studies }\end{array}$ \\
\hline $\begin{array}{l}\text { MPI-ESM-MR } \\
\text { MPI-ESM-LR }\end{array}$ & Max Planck Institute for Meteorology, Germany \\
\hline MRI-CGCM3 & Meteorological Research Institute, Japan \\
\hline $\begin{array}{l}\text { NorESM1-M } \\
\text { NorESM1-ME }\end{array}$ & Norwegian Climate Centre \\
\hline
\end{tabular}

